\title{
The Road to Recovery \#5: Self-Assessment of Virtual Facilitation to Build Trust ${ }^{1}$
}

\author{
Colby Silvert, Cody Gusto, John Diaz, and Glenn Israel ${ }^{2}$
}

This fifth publication in the Road to Recovery series discusses how Extension professionals can self-assess their techniques to build trust when facilitating virtual programming. Specific recommendations are provided addressing concerns about short- and long-term virtual trust, inclusion techniques, Zoom fatigue, and cybersecurity.

\section{Introduction}

It is still too early to predict how much of the shift to virtual and remote engagement imposed by COVID-19 will become permanent. However, many companies have already revised their policies and will permanently allow employees in certain positions to work from home or remotely (Minaya, 2020; Sytch \& Greer, 2020). Similarly, Extension professionals should be prepared for the prospect of permanent transitions to virtual delivery for many of their programs. There is thus a pressing need for educators and practitioners to refine skillsets to better adapt to virtual facilitation and evaluation. While we have learned a great deal about remote learning and facilitation since the onset of COVID-19, most available technical resources focus on formal educational contexts. Therefore, the Road to Recovery series was developed to provide relevant information and recommendations specifically tailored for Extension professionals.

Pandemics exacerbate physical health risks as well as emotional burdens and trauma for Extension professionals, clientele, and communities (Higgens, 2020; Israel et al., 2020; van Dorn, 2020). To address such challenges, the second article in this series (https://edis.ifas.ufl.edu/wc376) provided information and methods relevant for in-person and virtual engagement to respond to emotional and physical trust gaps clients may experience. Expanding on the previously introduced concepts of trust, the present article will review specific concerns and barriers related to building trust, security, and inclusion via live/real-time virtual platforms (e.g., Zoom).

\section{Reading the Virtual Room}

Many educators have experienced the uncomfortable feeling of not knowing exactly how the participants in a virtual training, meeting, or activity are really feeling. Are they engaged and excited? Are they tired and wanting to sign off? Reading the room when training or facilitating inperson involves observing body language, eye movements, and conversation patterns. Extension educators are likely accustomed to this type of audience analysis. According to Blum (2020), reading these movements and interactions is especially important when facilitating participatory learning activities (not lecture), and even interruptions and laughter are indicators of learners' enthusiasm and engagement.

While Zoom and similar platforms allow educators and participants the opportunity to see each other, remote

1. This document is AEC726, one of a series of the Department of Agricultural Education and Communication, UF/IFAS Extension. Original publication date March 2021. Visit the EDIS website at https://edis.ifas.ufl.edu for the currently supported version of this publication.

2. Colby Silvert, graduate assistant; Cody Gusto, graduate student; John Diaz, assistant professor and Extension specialist; and Glenn Israel, professor, Department of Agricultural Education and Communication; UF/IFAS Extension, Gainesville, FL 32611.

The Institute of Food and Agricultural Sciences (IFAS) is an Equal Opportunity Institution authorized to provide research, educational information and other services

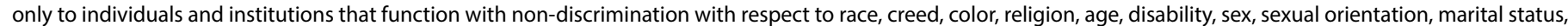

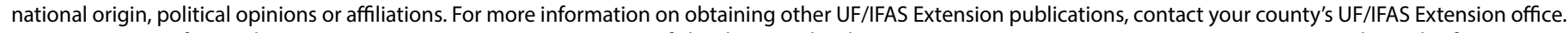
U.S. Department of Agriculture, UF/IFAS Extension Service, University of Florida, IFAS, Florida A \& M University Cooperative Extension Program, and Boards of County Commissioners Cooperating. Nick T. Place, dean for UF/IFAS Extension. 
engagement also encourages easy distractions (e.g., seeing 30 small faces on video instead of one, checking email, social media). Participants also cannot easily engage in active, passionate group conversation without talking over each other and causing disruptions; think of how often video-call participants apologize for interrupting someone or awkwardly pause to figure out who should talk next (Blum, 2020). Furthermore, "Zoom fatigue" is a real condition and commonly develops from overfocusing and stimulation without the visual and mental breaks we would take in person (Fosslien \& West Duffy, 2020). Finally, concerns about the handling and storage of personal data (i.e., user privacy) can adversely impact clients' virtual trust (Lee et al., 2020).

Given the barriers to engagement that Zoom and virtual platforms present, building trust with remote participants may seem like an arduous task. Nevertheless, virtual trust is the essential glue that connects you with remote clients, bridging geographic distance, and is especially crucial during a pandemic. You can adapt your current knowledge and skills and employ new techniques we introduce in this article to promote and evaluate virtual trust. To start, it is important to understand the forms of trust most relevant to virtual facilitation.

\section{Swift Trust}

When a group of learners or a new team first convene for a virtual learning activity or meeting, they may know very little about one another or the group instructor or leader. Yet in most cases, rather than dwelling in uncertainty or distance, participants give each other the benefit of the doubt-they want to trust one another (Germain \& McGuire, 2014). This initial atmosphere and feeling have been called swift trust, which Ferrazzi (2012) compares to the "honeymoon period of a relationship" (p. 1). Swift trust may diminish over time but is crucial in the first moments of facilitating a virtual program. Many techniques to build swift trust, described in more detail below under the section "Tips and Strategies," revolve around power dynamics. Research has indicated traditional, hierarchical power structures are less impactful in virtual spaces, and thus, efforts are needed to empower participants and level the power playing field (Ferrazzi, 2012). Rallying participants around clear, actionable goals is also vital when opening a program.

\section{Interpersonal Trust}

As swift trust and initial enthusiasm in virtual programming wane, interpersonal trust and longer-term relationship building become critical (Ferrazzi, 2012). Interpersonal trust is all about facilitating connections between participants, and according to Gambetta (1988), we trust those we feel are similar to us. Connecting participants is also a crucial opportunity to highlight the diversity and wealth of experiences and skills that clients bring to a program, which adult learning theory suggests boosts learning outcomes and participation (Knowles et al., 2015).

\section{Tips and Strategies}

The tips and strategies below concentrate on practical techniques Extension professionals can use to build swift trust and interpersonal trust in their facilitation of virtual programming. The checklist in Table 1 may be helpful for Extension professionals to apply these tips and strategies and self-assess their virtual trust efforts to improve participants' engagement, reduce effects of Zoom fatigue, account for cybersecurity, and foster inclusion and equity.

Table 1. Checklist of metrics to self-assess efforts to promote virtual trust.

\begin{tabular}{|c|c|c|}
\hline & Metric & $\begin{array}{l}\text { Yes } \\
\text { (Y) } \\
\text { or No } \\
\text { (N) }\end{array}$ \\
\hline 1. & $\begin{array}{l}\text { Actionable goals or learning objectives developed by } \\
\text { or at start of activity }\end{array}$ & \\
\hline 2. & $\begin{array}{l}\text { Participants' competencies and skills recognized } \\
\text { explicitly by the facilitator(s) }\end{array}$ & \\
\hline 3. & $\begin{array}{l}\text { Participants oriented on virtual platform and use of } \\
\text { key functions (e.g., chat box, raising hand) }\end{array}$ & \\
\hline 4. & $\begin{array}{l}\text { Icebreaker activity facilitated to engage participants } \\
\text { and encourage collaboration }\end{array}$ & \\
\hline 5. & $\begin{array}{l}\text { Power was shared among group using participatory } \\
\text { methods (e.g., breakout rooms) }\end{array}$ & \\
\hline 6. & $\begin{array}{l}\text { Breaks and/or energizers provided to reduce Zoom } \\
\text { fatigue }\end{array}$ & \\
\hline 7. & $\begin{array}{l}\text { A variety of delivery/facilitation methods used to } \\
\text { accommodate participants' diversity of learning styles } \\
\text { and emotional needs }\end{array}$ & \\
\hline 8. & $\begin{array}{l}\text { A safe space created to build comfort and emotional } \\
\text { trust }\end{array}$ & \\
\hline 9. & $\begin{array}{l}\text { Social networking (i.e., participants sharing photos } \\
\text { and information about themselves) used to facilitate } \\
\text { connections and interpersonal trust }\end{array}$ & \\
\hline 10. & $\begin{array}{l}\text { Best practices followed to ensure cybersecurity } \\
\text { and digital trust (i.e., data stored securely and only } \\
\text { collected with consent) }\end{array}$ & \\
\hline 11. & $\begin{array}{l}\text { Participants informed if activity recorded and/or } \\
\text { video, audio, or transcript shared publicly }\end{array}$ & \\
\hline
\end{tabular}


- Were you intentional in building swift trust in how you opened the program?

- When facilitating capacity building, especially for adult learners, active involvement by the participants in setting their own initial, actionable goals can build a collective sense of ownership over the learning (Knowles et al., 2015).

- Did you explicitly recognize the competencies and skills of your participants? When possible, doing so builds swift trust by making the virtual participants feel seen and valued (Ferrazzi, 2012).

- Did you encourage participants to actively engage in the program? Ensuring participants understand how to use the technology should be done by briefly reviewing instructions for raising your hand (which can help during discussions), using the chat to post ideas, and using the reactions feature in Zoom.

- Was an effective virtual icebreaker facilitated? According to Garmston (2013), often adult educators dive directly into content and instruction without first directing the attention of the participants. In doing this, they risk disengagement and loss of attention by the participants, which is especially likely to occur virtually. Additionally, an icebreaker provides a structure to allow participants to chitchat and visit briefly within a timeframe that will not interfere with the rest of the program.

- Adult educators can use an icebreaker to model collaboration and shared learning as well as begin light discussion on the topics and goals for the activity (Knowles et al., 2015).

- Virtual icebreakers can also ease anxiety and show your participants you care about them (Mrvova, 2020). The following resource provides some simple and fun icebreakers you can facilitate via Zoom: https://blog. sli.do/virtual-icebreakers/.

- Was power shared among all participants? While in some cases (e.g., virtual lectures and webinars), distributing power among participants is less feasible, when possible, decentralized power is more effective in virtual environments (Ferrazzi, 2012). Group work, discussions, and participants presenting or teaching are examples of methods to decentralize the power.

- Did you provide breaks or energizers to reduce the effects of Zoom fatigue on your participants? Breaks, especially during longer programs, are important for participants to turn off their cameras if they would like, grab a snack, and just step away from the screen. You can also facilitate energizers in real time to refocus attention and break up content. A Google search for Zoom energizers will produce fun and effective options to select from.

- Were your methods inclusive to the different learning styles and emotional needs of your participants?

- One delivery or facilitation method may be ideal for some participants and not for others. Hence, you should employ different types of activities such as presentations, breakout rooms, group reflections, the chat function, or share-screen interactive activities (Derek Bok Center for Teaching and Learning, n.d.).

- Hogan and Sathy (2020) provide eight excellent suggestions to embrace the diversity of virtual learners and design programs for broader reach and engagement: https://community.chronicle.com/ news/2333-8-ways-to-be-more-inclusive-in-yourzoom-teaching?cid=VTEVPMSED1.

- Clients may feel anxious and not know where to turn for information and guidance in a pandemic. Facilitating a safe space and reflection can build comfort and emotional trust (see the second article in this series for more recommendations related to safe spaces and emotional trust: https://edis.ifas.ufl.edu/wc376).

- Were meaningful connections made between you and your participants that will contribute to building interpersonal trust?

- When possible, facilitate some "social networking" to build connections among participants. For example, each participant could use photos and text to describe their backgrounds, interests, and goals and share them in a separate forum or via a presentation slide during a program.

- Breakout rooms for small group discussions and activities can also build interpersonal trust in a more intimate, lower-pressure atmosphere.

- Can your clients trust that their personal data and information are being safeguarded and handled ethically? Digital trust, accounting for the ethical and secure handling of personal data (Lee et al., 2020), is multifaceted and involves not only the identification and registration data of participants but also their contributions (spoken, text, etc.) during any virtual program.

- Zoom provides resources to support you in securing the learning environment: https://blog.zoom.us/ best-practices-for-securing-your-virtual-classroom/.

- Always seek consent and inform participants if a program will be recorded and if their information will be released publicly in any capacity. Explain what a recording or transcript will be used for and where it 
will be shared or posted and for how long. Participants should also be advised against taking their own screenshots or screen recordings without the consent of all participants.

- Were your participants satisfied with their experience in your virtual program? Warnock (1992) claimed asking Extension clientele, "how am I doing?" (p. 1) demonstrates openness and willingness to change, which in turn can build trust.

- It is advisable to send a post-evaluation to participants (i.e., a client satisfaction survey) via email or a link in Zoom or another platform. To evaluate participants' experience related to trust, clients can be asked whether they felt the items in Table 1 were accomplished in the virtual activity.

\section{Conclusion}

Building trust in a virtual environment is an essential first step toward impactful learning, relationship building, and understanding the needs of today's Extension clientele. Virtual education and engagement are rapidly advancing, and we are continuously learning and adapting with new techniques to improve participation and interpersonal connection. The concepts and methods discussed in this article address the gap in knowledge and resources specifically created for Extension professionals to conduct virtual facilitation and evaluation. For those interested in this topic, UF/IFAS Extension has compiled and produced additional resources and articles (including several in Spanish, Haitian Creole, and Mandarin) to support Extension professionals in addressing client needs related to the COVID-19 pandemic (https://edis.ifas.ufl.edu/topic_covid19).

\section{References}

Blum, S. (2020, April 22). Why we're exhausted by Zoom. Inside Higher Ed. https://www.insidehighered.com/ advice/2020/04/22/professor-explores-why-zoom-classesdeplete-her-energy-opinion

Ferrazi, K. (2020, October 8). How to build trust in a virtual workplace. Harvard Business Review. https://hbr. org/2012/10/how-to-build-trust-in-virtual

Fosslien, L., \& West Duffy, M. (2020, April 29). How to combat Zoom fatigue. Harvard Business Review. https://hbr. org/2020/04/how-to-combat-zoom-fatigue

Gambetta, D. (1988). Trust: Making and breaking cooperative relations. Basil Blackwell.
Garmston, R. J. (2013). The presenter's fieldbook: A practical guide. Rowman \& Littlefield.

Germain, M. L., \& McGuire, D. (2014). The role of swift trust in virtual teams and implications for human resource development. Advances in Developing Human Resources, 16(3), 356-370. https://doi.org/10.1177/1523422314532097

Higgins, T. (2020, March 27). Coronavirus pandemic could inflict emotional trauma and PTSD on an unprecedented scale, scientists warn. CNBC. https://www.cnbc. com/2020/03/27/coronavirus-pandemic-could-inflict-longlasting-emotional-trauma-ptsd.html

Hogan, K., \& Sathy, V. (2020, April 13). 8 ways to be more inclusive in your Zoom teaching. The Chronicle of Higher Education. https://community.chronicle.com/ news/2333-8-ways-to-be-more-inclusive-in-your-zoomteaching?cid=VTEVPMSED1

Israel, G. D., Diehl, D. C., Galindo, S., Ward, C., Ramos, A. K., Harrington, M., \& Kasner, E. J. (2020). Extension professionals' information use, protective behaviors, and work-life stress during the COVID-19 pandemic. Journal of Extension, 58(6), 5.

Knowles, M. S., Holton III, E. F., \& Swanson, R. A. (2015). The adult learner: The definitive classic in adult education and human resource development (8th ed.). Routledge.

Lee, J., Sniderman, B., Marquard, B., Galletto, N., Geeanpersadh, P., \& Cherny, M. (2020). Embedding trust into COVID-19 recovery. Deloitte Insights. https://www2. deloitte.com/us/en/insights/economy/covid-19/buildingtrust-during-covid-19-recovery.html

Minaya, E. (2020, April 3). CFOs plan to permanently shift significant numbers of employees to work remotely-Survey. Forbes. https://www.forbes.com/sites/ezequielminaya/2020/04/03/cfos-plan-to-permanently-shift-significantnumbers-of-employees-to-work-remotely---survey/

Mrvova, K. (2020, September 3). 20 best virtual icebreakers for your Zoom meetings. Slido. https://blog.sli.do/ virtual-icebreakers/

Sytch, M., \& Greer, L. (2020, August 18). Is your organization ready for permanent WFH? Harvard Business Review. https://hbr.org/2020/08/ is-your-organization-ready-for-permanent-wfh 
van Dorn, A., Cooney, R. E., \& Sabin, M. L. (2020). COVID-19 exacerbating inequalities in the US. The Lancet, 395(10232), 1243-44. https://doi.org/10.1016/ S0140-6736(20)30893-X

Warnock, P. (1992). Surveying client satisfaction. Journal of Extension, 30(1).

\section{Appendix: The Road to Recovery Series Overview}

The COVID-19 pandemic created the need for this Road to Recovery series of EDIS publications. Six publications are included, covering topics to assist Extension professionals and State specialists in addressing client needs and evaluating techniques for virtual engagement. Brief summaries of each publication in the series are provided below.

\section{The Road to Recovery \# 1: Introduction}

Summarizes the implications of the COVID-19 pandemic on Extension professionals' operations and presents necessary adaptations and key considerations to safely improve delivery and impact.

\section{The Road to Recovery \#2: Building Physical and Emo-} tional Trust When Engaging with Extension Clientele Provides information and recommendations to address emotional and physical trust gaps clientele may experience in the face of a pandemic by using intentional, strategic efforts when engaging in the field or via virtual platforms.

\section{The Road to Recovery \#3: Facilitating Community} Resilience for Effective Pandemic Response

Considers challenges posed by the pandemic and the importance of community-led initiatives and provides alternative strategies for facilitating building resiliency, capacity, and social capital involving community stakeholders and clients.

\section{The Road to Recovery \#4: Evaluating Virtual Techniques} to Reach Clientele and Promote Equity

Offers guidance on how to effectively assess which audiences are being reached through virtual engagement and which audiences may be "falling through the cracks;" includes information on leveraging social media and virtual platform analytics, applying audience segmentation, and using online surveys and polls.

\section{The Road to Recovery \#5: Self-Assessment of Virtual} Facilitation to Build Trust

Provides information on how educators can self-assess their efforts to facilitate trust through remote learning and virtual engagement, especially important during a pandemic; considers users' concerns about cybersecurity and common anxieties, discomfort, and competency gaps using online platforms.

\section{The Road to Recovery \#6: Evaluating Virtual Strategies to} Build Community Capacity and Resilience

Offers support for agents interested in evaluating their use of virtual strategies to promote participatory engagement and community capacity building; provides recommendations for agents to better assess whether virtual techniques improve users' perceptions of collective efficacy and community capacity during pandemic scenarios. 